Buychik, A. (2020). Allocation of basic research in the field of cultural heritage preservation in a separate scientific direction. Eurasia: Current Issues of Cultural Heritage. European Scientific e-Journal, 3(3), 5-13. HlučínBobrovníky: "Anisiia Tomanek" OSVČ.

DOI: $10.47451 /$ her2020-12-005

The paper is published in Crossref, ICI Copernic, BASE, Zenodo, OpenAIRE, LORY, HSLU, J-Gate, Academic Resource Index ResearchBib, ISI International Scientific Indexing, eLibrary, Mendeley, and WebArchive databases.

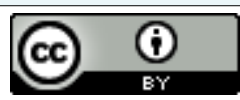

Alexander Buychik, Doctor of Science in Economics, PhD of Social Sciences, Chief Director for Science, Tuculart Holding. Ostrava-Hlučín, Czech Republic. ORCID 0000-0002-2542-4198.

\title{
Allocation of basic research in the field of cultural heritage preservation in a separate scientific direction
}

Abstract: Over the past 150 years, active work has been carried out to form the basis for the restoration and preservation of the objects of art that bear a specific cultural code of humanity as a whole and each nation individually. Despite the fact that the first restoration work known to us today, were held around $1400 \mathrm{BC}$, states and leading statesmen did not attach due importance to the preservation of the heritage of the past for many centuries. The author of the article considers topical issues of development of a unified new science of cultural heritage preservation - Klironomy - and the definition of theoretical sciences that should become the basis for the formation of a new scientific field. The sciences of culture and art based on philosophical thought have already created the necessary foundation for the formation of a separate complex of Cultural Heritage Sciences rather than a scientific trend. The author concludes that the preservation of cultural heritage has long outgrown the conditional study of individual areas of activity - restoration, conservation, renovation and revitalization. In the early 21 st century need to this question to look from a new perspective and to consider the preservation of tangible and intangible cultural heritage as part of cultural and art sciences, and some complex science.

Keywords: cultural heritage, preservation, klironomy, restoration, conservation, renovation, revitalization.

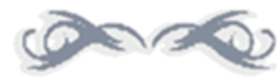

\section{Introduction}

Over the past 150 years, active work has been carried out to form the basis for the restoration and preservation of the objects of art that bear a specific cultural code of humanity as a whole and each nation individually. Despite the fact that the first restoration work known to us today, were held around $1400 \mathrm{BC}$, states and leading statesmen did not attach due importance to the preservation of the heritage of the past for many centuries (Buychik, 2019a).

However, it should be noted that so far, no university in the world has formed a single set of academic disciplines that could be designated as aimed at developing knowledge, skills and abilities in the field of preserving tangible and/or intangible cultural heritage for future specialists at the bachelor or master's level.

For the $20^{\text {th }}$ century, the basic concepts and provisions on the preservation of the tangible and intangible cultural heritage of mankind were formulated. Numerous charters, enshrined in UNESCO documents, served as the basis for the formation of the scientific direction of 
conservation and restoration and the inclusion of new science in the disciplinary cycles of many universities in Europe and America that train specialists in this field (Buychik, 2019a).

Thus, at the beginning of the $21^{\text {st }}$ century, there was a need to create a unified science on the preservation of cultural heritage, which would provide for the study of all aspects of tangible and intangible heritage to train specialists in a new format.

Cultural heritage is characterized by a number of objective characteristics. Cultural heritage is the legacy of physical artifacts and intangible attributes of a group or society that is inherited from past generations. Not all legacies of past generations are 'heritage', rather heritage is a product of selection by society (Logan, 2007). Cultural heritage includes tangible culture such as buildings, monuments, landscapes, books, art works, and artifacts, intangible culture such as folklore, traditions, language, and knowledge, and natural heritage, including culturally significant landscapes, and biodiversity (Sullivan, 2016).

The deliberate act of keeping cultural and heritage from the present for the future is known as preservation, which cultural and historical ethnic museums and cultural centers promote, though these terms may have more specific or technical meaning in the same contexts in the other dialect. Preserved heritage has become an anchor of the global tourism industry, a major contributor economic value to local communities (Logan, 2007).

Protection of cultural heritage or protection of cultural goods means all measures to protect cultural property against damage, destruction, theft, embezzlement or other loss. The term "monument protection" is also used for immovable cultural property (Wegener \& Otter, 2008). This relates in particular to the prevention of robbery digs at archaeological sites, the looting or destruction of cultural sites and the theft of works of art from churches and museums all over the world and basically measures regarding the conservation and general access to our common cultural heritage (O'Keefe, 2016). Legal protection of cultural heritage comprises a number of international agreements and national laws, and these must also be implemented.

Thus, the sciences of culture and art based on philosophical thought have already created the necessary foundation for the formation of a separate complex of Cultural Heritage Sciences rather than a scientific trend.

\section{Systematic scientific approach to the preservation of cultural heritage}

The cultural image of a society cannot be formed out of nowhere, from scratch. This is the result of centuries - old transformations, diffusions and interpenetrations of semiotic series, traditions, folklore, the formation of intangible cultural heritage and its transfer to the material shell, which begins to form the concept of heritage value, first in economic perception (equivalent), and then in spiritual perception-the value of the past for society in the future (Buychik, 2020a).

In connection with the increasing globalization of society, the central axiological concept of 'values' in the field of culture remains an important element of preserving national cultural identity. It, in turn, forms the concept of 'cultural value', through which - the definition of the category of 'cultural heritage', based on the totality of cultural values defined by each civilization within the framework adopted by this society (Buychik, 2019b).

Over the past centuries, man has developed a large amount of theoretical, theoreticalpractical and methodological material, which served as the basis for the formation of a 
klironomical scientific direction, distinguished on the border of cultural, art and historical Sciences with signs of cross-border with the natural Sciences (chemistry and physics) and philosophy (Buychik, 2019b).

Also, the allocation of a separate Science of Klironomy is extremely important to ensure the correct definition of the educational complex in the training of specialists (bachelors) in the field of preservation of architectural objects, sculptures, decorative and applied arts as an integral part of the traditional art and culture of mankind. It is absolutely unacceptable to train specialists in a scientific field that does not clearly belong to one of the classical sciences.

Consequently, Klironomy as a new fundamental science about the preservation of cultural heritage, will include the whole complex of research areas. Klironomy will become the new crossborder scientific discipline at the intersection of natural, humanitarian and socio-economic sciences.

In Klironomy, three main functions can be defined:

1. Preservation of all types of cultural heritage of the society.

2. Restoration of damaged or partially lost parts of objects, objects or elements of cultural heritage.

3. Reconstruction of lost objects, objects or elements of cultural heritage (Buychik, 2019d).

Also, it should analyze various methods of the research in the field of cultural heritage's preservation, So, the main methods can be selected:

1. Axiological method allows you to determine the value of an object, object or element of culture and classify it as part of the cultural heritage of society.

2. Analytical method makes it possible to analyze the main stages of creation and existence of an object, object or element of cultural heritage with the aim of a competent approach to its preservation or restoration.

3. Synthesis makes it possible to link the achievements of human thought isolated from various sciences into a single whole in order to use them in the preservation of objects, objects and elements of cultural heritage.

4. Comparative analysis serves as a basis for determining the main directions of cultural heritage preservation - restoration, conservation and renovation-and their separation in the process of choosing one of the directions.

5. System analysis makes it possible to differentiate individual sciences within a given scientific direction and determine the pathways and interactions of the Klironomical Sciences (Buychik, 2019a).

Since the purpose of Klironomy as a science is the preservation of sites, objects and items of cultural heritage, it can be determined the task of the science:

- perform a description of the state of objects, objects and elements of cultural heritage for the relevance and volume of restoration work;

- analyse the state of objects, objects and elements of culture and art for their inclusion in the list of cultural heritage and categorization;

- develop methods for preserving, restoring and reconstructing objects, objects and elements of cultural heritage; 
- form a scientific base, conduct scientific and educational activities and prevent the preservation of cultural heritage in society (Buychik, 2019a).

During the development of the Science of Klironomy were differentiated scientific direction. Klironomy, as the science of preserving cultural heritage in general, considers three basic directions for the formation of knowledge about cultural heritage. Consequently, Klironomy includes three scientific klironomical directions of its development:

- Tactile Klironomy, i.e., the direction of Klironomy of tangible cultural heritage;

- Facile Klironomy, i.e., the direction of klironomy of intangible (spiritual) cultural heritage;

- Theoretical Klironomy, i.e., the direction, which studies general issues and problems of achievement of cultural heritage's preservation.

Thus, Klironomy as a complex science can be distinguished from the number of cultural, art and social Sciences and Humanities and considered as a new intersectoral science that studies the preservation of various types of cultural heritage.

\section{The system of the sciences of Theoretical Klironomy}

Special place in system of klironomical sciences (Figure 1) is the direction of the Theoretical Klironomy. Theoretical Klironomy is a special scientific direction of Klironomy cultural heritage of society. In contrast to Tactile and Facile Klironomy, directions which combine the applied science of Klironomy, i.e., a body of knowledge in which research and discoveries have a direct orientation to practice and provide the development of new technologies - algorithms of action to obtain the desired product, theoretical klironomy deals with the creation of the basis of all science-history, methodology, systematics and statistics in the field of preservation of objects and elements of cultural heritage - tangible and intangible (Buychik, 2019a).

The object of research in the scientific direction: objects and elements of tangible and intangible cultural heritage. The subject of research in the scientific direction: history, methodology, statistics and systematics of tangible and intangible and cultural heritage's preservation. The purpose of the scientific direction: development of theoretical bases of Klironomy as a science about preservation of tangible and intangible cultural heritage.

According to purpose of the scientific direction, the main tasks of the scientific direction can be detected as:

- perform historical analysis of human and society activity in the field of cultural heritage preservation;

- develop a methodology for the formation of the scientific directions of Tactile and Facile Klironomy;

- perform statistical research in the field of the Tactile and Facile Klironomical directions, i.e., objects, items and elements of cultural heritage, as well as methods and techniques of their conservation, restoration, renovation and revitalization;

- systematise the received statistical data in the field of cultural heritage preservation (Buychik, 2019a).

In modern view of the scientific direction of Theoretical Klironomy, six klironomical sciences can be detected: 
1. Historical klironomy is a klironomical science of sociological research in the field of human evolution knowledge regarding the understanding of cultural heritage preservation. Historical research is an important and integral part of the development of any science and understanding of human thought evolution in the temporal stream. It is necessary to adhere to one of the main historical methods to realize historical research in a scientific perspective.

2. Analytical Klironomy is a klironomical science developing the theoretical foundations of klironomical analysis in the field of knowledge of human evolution regarding the understanding of cultural heritage preservation. Statistics and analysis are important components of every science. The formation of statistical data in the klironomy is manifested in the collection of the facts of cultural heritage preservation expressed in archaeological artifacts, objects and items of tangible cultural heritage, as well as in the elements of intangible cultural heritage.

3. Methodology of Klironomy is klironomical science, designing and developing different methods of justification of the klironomical sciences. Methodology of Klironomy works closely with Historical and Analytical Klironomy. Methodology of Klironomy plays an important role in the development of theoretical approach to the development of klironomical sciences on preservation of tangible cultural heritage objects, as well as the elements of intangible cultural heritage and the re-establishment of a unified picture of social life and nations as in a certain moment of history and temporal changes.

4. Philosophy of Klironomy is a klironomical science that studies social and philosophical thought on the preservation of cultural heritage of society temporally, i.e., throughout its existence. Philosophy of Klironomy plays one of the most important roles in the formation of theoretical approach to the development of the klironomical sciences on the preservation of the objects of tangible cultural heritage, as well as the elements of intangible cultural heritage and the reestablishment of a unified picture of social life and nations as in a certain moment of history and temporal changes.

5. Geography of Klironomy is a klironomical science that studies territorial location and distribution the objects and elements of cultural heritage regionally and globally. Geography of Klironomy plays one of the most important roles in the formation of theoretical approach to the development of the klironomical sciences on the preservation of the objects of tangible cultural heritage, as well as the elements of intangible cultural heritage because shows the dynamics of territorial development or depression of cultural heritage preservation.

6. Juristic Klironomy is a klironomical science that studies problems of legislative acts in the field of cultural heritage preservation. Juristic Klironomy is one of the most important klironomical sciences, since it not only analyzes the legal framework of various states for compliance with the goal of maximum preservation of cultural heritage, but also considers the dynamics of the development of the legal field in relation to certain types of tangible and intangible heritage.

Thus, the direction of Theoretical Klironomy is formed as an independent direction of sciences aimed at studying the basics of preserving cultural heritage. Each of these sciences has its own goal, list of tasks, methodological apparatus and functionality. 


\section{Conclusion}

Thus, the preservation of cultural heritage has long outgrown the conditional study of individual areas of activity - restoration, conservation, renovation and revitalization. The success of the American scientific school, which in the 1980s was the first to single out restoration and conservation as a separate field to train specialists, is already archaic and does not meet the requirements of a modern approach to the issue of cultural heritage. The approach to training specialists in this field in Europe and East Asia as centers of accumulation of a large number of tangible and intangible cultural heritage is also absolutely archaic. The absolute lag in this direction of formation of the klironomical worldview (Buychik, 2020a) is shown by Russia, which still does not even train specialists in the field of renovation and revitalization.

In fact, the leading states in the field of cultural heritage protection have already reached a dead end in the development of this direction in the classical way of the 19th century. In the early 21st century need to this question to look from a new perspective and to consider the preservation of tangible and intangible cultural heritage as part of cultural and art sciences, and some complex science, which can be described in one word: "Klironomy".

The sciences of Theoretical Klironomy are designed to develop the basis of the complex of sciences on the preservation of cultural heritage and create a scientific platform for the future training of specialists in the field of restoration, conservation, renovation and revitalization.

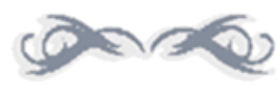

\section{References:}

Buychik, A. (2019a). Klironomy as a science of preservation of cultural heritage. Mauritius, France, Germany: LAP Lambert Academic Publishing.

Buychik, A. (2019b). Philosophical understanding of the value of historical and cultural heritage. Series of Cognition. Modern Science: Actual Problems of Theory and Practice, 6, 103-106. Moscow.

Buychik, A. (2019c) The problem of formation of klironomy as a science of the preservation of cultural heritage. Science in the Modern World. Collection of publications of the multidisciplinary scientific journal Archivarius in Kiev: collection of articles (standard level, academic level). Multidisciplinary scientific journal, 12(45), 28-31. Kiev: The Archivarius.

Buychik, A. (2019d). Klironomy as a science about preservation of historical and cultural heritage. Series of cognition. Modern Science: Actual Problems of Theory and Practice, 3, 90-93. Moscow.

Buychik, A. (2020a). Formation of the concepts of cultural, art history and klironomical outlook as the basis for educating a person of culture and art. The Materials of the International Scientific Forum "Education. Science. Culture" (November 20, 2019). In 5 parts. Part 2. International Scientific and Practical Conference "Pedagogy and Psychology in the Modern System of Education": Collection of Scientific Articles, 91-92. Gzhel: GSU.

Buychik, A. (2020b). Klironomy as a systematic scientific approach to the preservation of cultural heritage: its place in the educational system. Scientific Trends: Philology, Cultural Studies, Art History. Collection of scientific papers based on the materials of the 19th international scientific and practical conference, 29-34. St Petersburg: CSP IUAS Publishing House. 
Buychik, A., Lebedev, S. (2017). Traditional applied art in Russia in the 21st century: opportunities and prospects for development. Online Electronic Scientific Journal "Vestnike GSU”, 2. Gzhel State University.

Logan, William S. (2007). Closing Pandora's Box: Human Rights Conundrums in Cultural Heritage. In Silverman, Helaine; Ruggles, D. Fairchild. (Eds.). Cultural heritage and human rights. New York, NY: Springer.

O’Keefe, R., Peron, C., Musayev. T., Ferrari, G. (2016). Protection of Cultural Property. Military Manual. UNESCO.

Sullivan, A. M. (2016). Cultural Heritage \& New Media: A Future for the Past. 15 J. MARSHALL REV. INTELL. PROP. L. 604.

Wegener, C., Otter, M. (2008). Cultural Property at War: Protecting Heritage during Armed Conflict. In The Getty Conservation Institute, Newsletter 23.1, Spring.

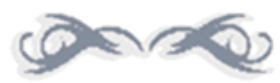

\section{Appendix}

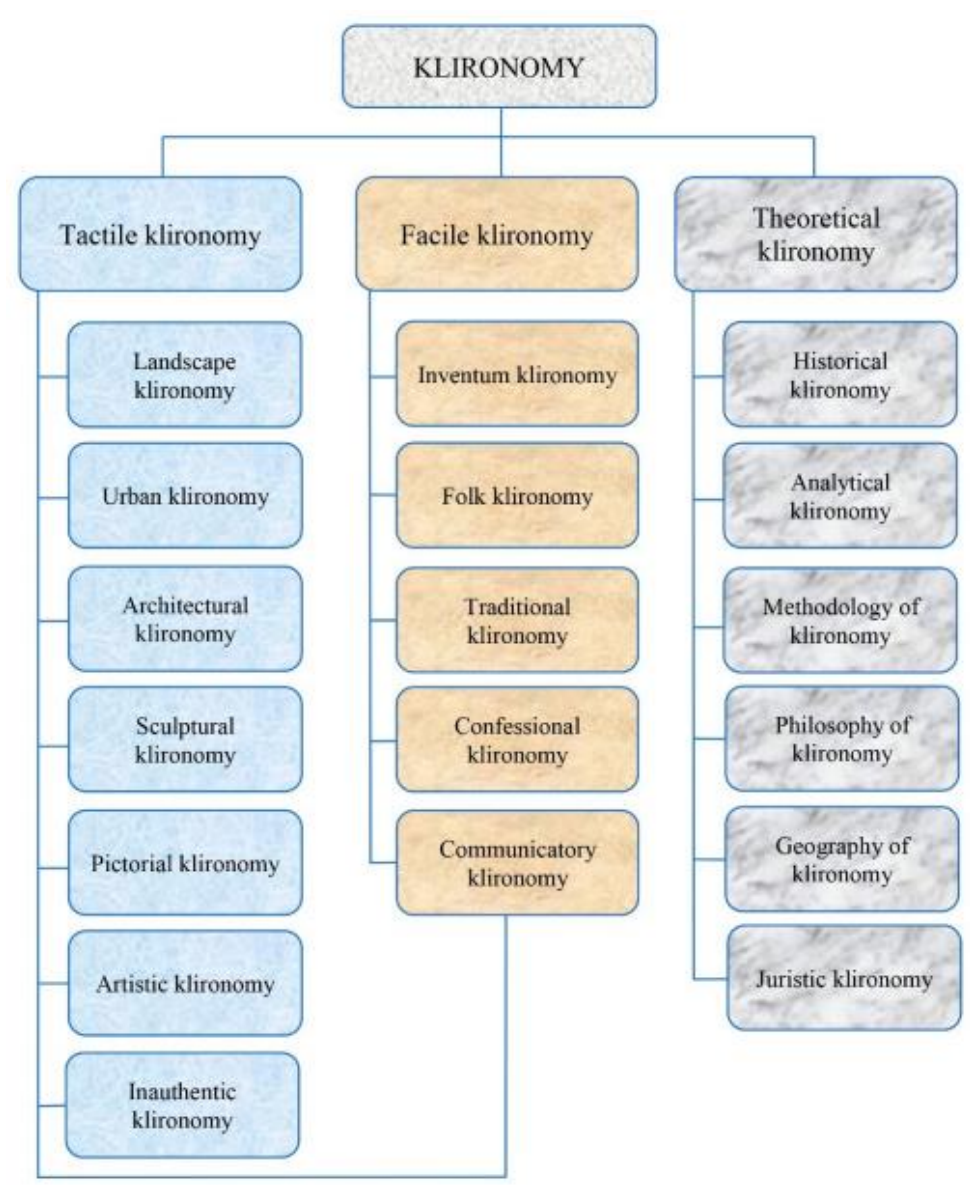

Figure 1. The system of klironomical sciences 